\title{
Specific micronutrient concentrations are associated with inflammatory cytokines in a rural population of Mexican women with a high prevalence of obesity
}

\author{
Gerardo Zavala ${ }^{1}$, Kurt Z. Long ${ }^{2}$, Olga P. García ${ }^{1}$, María del Carmen Caamaño ${ }^{1,3}$, Tania Aguilar ${ }^{1}$, \\ Luis M. Salgado ${ }^{4}$ and Jorge L. Rosado ${ }^{1,3 *}$ \\ ${ }^{1}$ Facultad de Ciencias Naturales, Universidad Autónoma de Querétaro, Av de la Ciencia S/N, Juriquilla, Querétaro, \\ Qro, CP 76230, Mexico \\ ${ }^{2}$ School of Population Health, University of Queensland, Queensland, Australia \\ ${ }^{3}$ CINDETEC A.C., Querétaro, Qro, Mexico \\ ${ }^{4}$ CICATA, IPN, Querétaro, Qro, Mexico
}

(Submitted 18 November 2011 - Final revision received 13 April 2012 - Accepted 15 April 2012 - First published online 29 May 2012)

\section{Abstract}

It has been recognised recently that obese individuals have lower concentrations of micronutrients and this may affect the concentrations of inflammatory cytokines. A cross-sectional study was carried out to evaluate the association of specific micronutrients' status with chronic inflammation caused by obesity in 280 women (36.1 (SD 7.5) years) from seven rural communities in Mexico. Measurements of weight, height and waist circumference were made on all women and body composition was determined by dual-energy X-ray absorptiometry. Concentrations of the cytokines IL-1, TNF- $\alpha$, IL-6, IL-10 and IL-12, lipid profile, and the micronutrients Zn and vitamins A, C and E were determined in fasting blood samples. Ordered logistic regression models were used to determine associations between categorised cytokine levels and micronutrients. It was found that $80 \%$ of women were overweight or obese, and had significantly higher concentrations of $\mathrm{C}$-reactive protein than normal-weight women $(P=0.05)$. The risk of higher levels of TNF- $\alpha$, IL- 6 , IL-10 and IL-12 was reduced significantly among women with higher $\mathrm{Zn}$ concentrations (OR $0 \cdot 63,95 \% \mathrm{CI} 0 \cdot 42,0 \cdot 96, P=0 \cdot 03$; OR 0.57, 95\% CI 0.39, 0.86, $P=0 \cdot 025$; OR $0 \cdot 63,95 \%$ CI $0.41,0 \cdot 96, P=0.04$; OR $0.62,95 \%$ CI $0 \cdot 41,0 \cdot 95, P=0.03$, respectively). Higher concentrations of vitamin A were slightly associated with reduced risks of higher levels of IL-1 and IL-12 (OR 0.97, $95 \%$ CI 0.95, 0.99, $P=0 \cdot 03$; OR 0.97, 95\% CI 0.94, 0.99, $P=0 \cdot 03$, respectively); when adjusting for BMI, this association was lost. No associations were found between vitamin C or vitamin E:lipids concentrations and inflammatory cytokines. In conclusion, higher Zn concentrations are associated with reduced risks of higher concentration of inflammation markers in a population of women with a high prevalence of obesity.

Key words: Cytokines: Micronutrients: Obesity

The growing burden of obesity-associated chronic diseases is now one of the more important health issues in the world. Obesity and excess abdominal fat are risk factors for a broad range of chronic diseases such as hypertension, CVD and type 2 diabetes mellitus, all of which are now the principal causes of mortality worldwide ${ }^{(1-3)}$. The burden of this complex of diseases is now becoming an acute problem in industrialising countries passing through an epidemiological and nutrition transition. Mexico, for example, is one of the countries with the highest prevalence of obesity, as found in a 2006 National Nutrition Survey of Mexico (Encuesta Nacional de Salud y Nutrición; ENSANUT 2006), and this prevalence is increasing year after year ${ }^{(4)}$.

Obesity has been described as a form of low-grade inflammation $^{(5)}$. Inflammatory cytokines such as TNF- $\alpha$, IL- 1 and IL-6, which are important risk factors for chronic diseases, are elevated in obese individuals. These cytokines are principally produced through signalling pathways located within the adipocytes that make up the white adipose tissue. Their circulating concentrations directly correlate with adipocyte size and number $^{(6)}$. Leptin, an adipokine that promotes the sensation of satiety, plays an important role in promoting the expression of such inflammatory cytokines ${ }^{(7)}$. Also, leptin is involved in

Abbreviations: CRP, C-reactive protein; Th, T-helper; UAQ, Universidad Autónoma de Querétaro; ZAG, Zn- $\alpha 2$-glycoprotein.

*Corresponding author: J. L. Rosado, fax +52 442234 2958, email jlrosado@prodigy.net.mx 
the activation and infiltration of macrophages into white adipose tissue ${ }^{(6)}$, the activation of natural killer cells ${ }^{(8)}$, and suppresses the proliferation of $\mathrm{CD}^{+}{ }^{+}$and $\mathrm{CD} 25^{+}$Treg cells $^{(9)}$, and also regulates the T-helper (Th) 1 and Th2 response ${ }^{(10)}$.

Micronutrient status is associated with obesity and may have an important effect on the inflammatory response ${ }^{(11)}$. Studies have shown that low $\mathrm{Zn}$ serum concentration is associated with an increased risk of being obese ${ }^{(11)}$. Zn may regulate the inflammatory response by up-regulating leptin synthesis, by directly activating monocytes, or through its role in $\mathrm{Zn}-\alpha 2$-glycoprotein (ZAG) which is involved in TNF- $\alpha$ transcription ${ }^{(12,13)}$. A vitamin A-deficient diet in animal models is associated with increased leptin expression in white adipose tissue and brown adipose tissue ${ }^{(14,15)}$. Vitamin $\mathrm{A}$ and its active metabolites inhibit the inflammatory Th1 response and promote the Th2 response $^{(16)}$. Vitamin $\mathrm{E}$ has also been found to function as an anti-inflammatory agent in studies concerned with inflammation and pulmonary function in asthma patients as well as inflammation in rats with induced asthma ${ }^{(17,18)}$. Vitamin $C$ has been shown to have anti-inflammatory effects by reducing $\mathrm{C}$-reactive protein (CRP) serum concentrations ${ }^{(19,20)}$. It is still not clear what effect each micronutrient has on these inflammatory response pathways among individuals who differ in adiposity and body mass. Also, studies have shown that the intake of certain foods, such as legumes, whole grains, fruits and vegetables, that have a high content of micronutrients including $\mathrm{Zn}$, and vitamins $\mathrm{A}, \mathrm{C}$ and $\mathrm{E}$, have been associated with lower markers of inflammation ${ }^{(21-23)}$.

The objective of the present study was to examine how micronutrient blood concentrations and measures of adiposity are associated with the inflammatory response among Mexican women with a high prevalence of overweight and obesity. The further clarification of this relationship could lead to the development of new preventive and therapeutic micronutrient interventions that contribute to the reduction in the burden of obesity and its complications.

\section{Experimental methods}

\section{Study population}

The population for this study was 280 women, 25-55 years of age, who resided in six rural communities located within the Mexican State of Querétaro. Women were excluded from the study if they had uncontrolled diabetes, if they had received treatment for obesity or had taken vitamin and mineral supplements in the previous 3 months. Pregnant and lactating women, as well as women who had any type of eating disorder, were also excluded from the study. The present study was conducted according to the guidelines laid down in the Declaration of Helsinki and all procedures involving human subjects/patients were approved by the Human Research Committee of the School of Natural Sciences at the Universidad Autónoma de Querétaro (UAQ). Written informed consent was obtained from all subjects/patients.

The sample size of 280 subjects in this study was intended to find a significant OR of 0.50 or 1.75 between two independent groups with different concentrations of cytokines, with an $\alpha$ error of $5 \%, \beta$ error of $20 \%$, and an estimated prevalence of a micronutrient deficiency of $20 \%{ }^{(24)}$.

\section{Study design}

This study was cross-sectional in design, in which all enrolled women were first interviewed during an initial household visit to determine clinical histories of chronic disease. Subsequently, these women were then transported at different dates to the Metabolic Unit at the School of Natural Sciences within UAQ, where anthropometric and body composition determinations were made in one session.

A single, basal $5 \mathrm{ml}$ blood sample was drawn from all women who had been fasting for the previous $12 \mathrm{~h}$ for the determination of glucose concentrations, lipid profile, Zn, vitamins $\mathrm{A}, \mathrm{C}$ and $\mathrm{E}$ concentrations and concentrations of inflammatory and adaptive immune response cytokines. These samples were collected from the women, at the local health clinic in their respective communities.

\section{Anthropometry and body composition methods}

The women wearing light clothing were weighed using a scale (SECA ONDA Mod 843; SECA) with a precision of $1.0 \mathrm{~g}$, while their stature was determined with a precision of $0 \cdot 1 \mathrm{~cm}$ using a portable stadiometer (SECA Mod 206; SECA). Hip circumference was determined with a precision of $0 \cdot 1 \mathrm{~cm}$ using flexible metal tapes (SECA Mod 200; SECA). All measurements were done, non-consecutively, in duplicate by personnel, that had been previously standardised in their application according to procedures developed by Lohman et al. ${ }^{(25)}$. Women were then categorised as normal weight $\left(\mathrm{BMI}<24.9 \mathrm{~kg} / \mathrm{m}^{2}\right.$ ), overweight (BMI between 25.0 and $29.9 \mathrm{~kg} / \mathrm{m}^{2}$ ) and obese $\left(\mathrm{BMI}>30 \cdot 0 \mathrm{~kg} / \mathrm{m}^{2}\right)$, using the WHO classification system ${ }^{(26,27)}$.

Body composition determinations, percentage of body fat and percentage of abdominal fat, were carried out during this session using DEXA (Hologic, Mod Explorer) in the Metabolic Unit of UAQ, by a certified technician. High body fat was considered with values $\geq 30 \%$ of total body mass ${ }^{\text {(28) }}$. Abdominal fat was obtained as described previously ${ }^{(29)}$. Briefly, abdominal fat is determined from a $10 \mathrm{~cm}$ rectangle that is drawn in the X-ray body diagram, immediately above the ileac crest of the subject and it is extended to the sides over the border of the subject's anatomy.

\section{Laboratory methods}

Leptin and C-reactive protein determinations. Concentrations of leptin and CRP in plasma were measured in duplicate using commercial ELISA kits (Human Leptin Elisa Kit, Linco Research; High Sensitivity C-Reactive Protein Elisa Kit, Bioquant).

Determination of inflammatory and adaptive immune response cytokines. The concentrations of the inflammatoryrelated cytokines, IL-1 $\beta$, IL-6, IL-8, TNF and IL-12p70, and the anti-inflammatory cytokine IL-10 were measured simultaneously using flow cytometry analysis with the human inflammation kit (Becton Dickinson). Briefly, the serum 
samples $(50 \mu \mathrm{l})$ were incubated $1.5 \mathrm{~h}$ in the dark with the appropriate dilution of the capture beads, which were then washed by centrifugation and followed by their incubation for an additional $1.5 \mathrm{~h}$. The beads were then washed again by centrifugation and quantified in a FACSCAN (Becton Dickinson) equipped with a $488 \mathrm{~nm}$ laser. The data were analysed using the BD CellQuest software, with positive controls provided by the supplier.

Determination of zinc in plasma. Zn concentrations in plasma were measured using flame atomic absorption spectrophotometry (Perkin Elmer, Mod. Analyst 700) using the corresponding certified standards. Zn deficiency was defined as plasma concentrations of $<700 \mu \mathrm{g} / \mathrm{l}^{(30)}$.

Determination of vitamins $A, E$ and $C$ in plasma. Vitamins $\mathrm{A}$ and $\mathrm{E}$ were simultaneously determined by reversed-phase HPLC (WATERS) using a C18 column (WATERS) with a mobile phase of $100 \%$ methanol (J. T. Baker) and a $1 \mathrm{ml} / \mathrm{min}$ flow with a temperature of $40^{\circ} \mathrm{C}$, measured at a wavelength of $300 \mathrm{~nm}$. Vitamin C was measured by HPLC (WATERS), using a C18 column (WATERS) with a mobile phase of $0.01 \mathrm{M}-\mathrm{NaH}_{2} \mathrm{PO}_{4}$ and $0.2 \mathrm{~mm}$-EDTA, a $0.85 \mathrm{ml} / \mathrm{min}$ flow, and measured at a wavelength of $254 \mathrm{~nm}$.

Determination of glucose and lipid profile. Fasting glucose concentration was measured by an enzymaticcolorimetric method using the commercial kit Glucose-PAP (Elitech) with a Clinical Analyser Bayer RA-50 (Bayer Diagnostics). Plasma concentration of total cholesterol, HDL and total TAG were measured using commercial kits (Cholesterol SL, Triglycerides, Cholesterol HDL SL 2G, Elitech) in a Bayer RA-50 Analyzer (Bayer Diagnostics). LDL was calculated from the previously mentioned data using the Friedewald $\operatorname{method}^{(31)}$.

Biochemical and immunological assays of all samples were carried out in duplicate in the Human Nutrition Laboratory in the School of Natural Sciences at UAQ.

\section{Data analysis}

Data were entered in Excel (Microsoft), verified, and checked for range and consistency. Women were considered Zn-deficient if they had plasma concentrations below $700 \mu \mathrm{g} / \mathrm{l}^{(30)}$, and vitamin A-deficient if they had plasma concentrations $<200 \mu \mathrm{g} / \mathrm{l}^{(32)}$. Women were classified as vitamin E-deficient if they had concentrations $<5 \mu \mathrm{g} / \mathrm{ml}$ or $<2.4 \mu \mathrm{mol} \alpha$-tocopherol:mmol lipid, and finally, vitamin C-deficient if they had plasma concentrations $<2 \mu \mathrm{g} / \mathrm{ml}^{(32,33)}$. Women were classified as having high glucose if they had a fasting plasma concentration of glucose above $1260 \mathrm{mg} / \mathrm{l}^{(34)}$. Women were classified with normal lipid concentration if they had cholesterol $<2000 \mathrm{mg} / \mathrm{l}$, TAG $<1500 \mathrm{mg} / \mathrm{l}$ and HDL-cholesterol $>350 \mathrm{mg} / \mathrm{l}^{(35)}$.

The primary end points for this analysis were the plasma concentrations of pro- and anti-inflammatory cytokines and chemokines among all enrolled women from whom blood samples were taken. Means and standard deviations of physical and biochemical characteristics of enrolled women were first determined to summarise the data.
Associations between measures of obesity, total body fat in $\mathrm{kg}$ and percentage, and abdominal fat and plasma concentrations of the pro-inflammatory cytokines IL-1, IL-6, IL-8, IL-12, TNF- $\alpha$ and the anti-inflammatory cytokine IL-10 cytokine were determined as a first step in the overall analysis. Conventional analytical techniques could not be used to analyse these cytokines as endpoints, since an important proportion of samples had no detectable concentration of cytokines. Accordingly, ordered logistic regression analyses were used, which models the probability distributions of cytokine values categorised into three levels ordered from lowest to highest: undetectable, $<$ median of positives, $>$ median of positives $^{(36)}$. The inclusion of BMI, abdominal fat (\%) and waist-to-height index in the model tested the hypothesis that the probability distributions of categorised cytokine values will differ according to differences in these measures expressed as an OR. Ordinal logistical analyses were then carried out to determine the associations between leptin with the pro-inflammatory and anti-inflammatory cytokines. Leptin analysis was controlled for age and CRP concentrations. These analyses were meant to determine whether leptin is the intermediate mechanism underlying the associations between measures of obesity and body fat and cytokine plasma concentrations.

A final set of analyses was then carried out to test the hypothesis that the probability distributions of categorised cytokine values will vary by differences in the micronutrient plasma concentration again expressed as an OR. As such, analyses were first carried out with the variables for plasma concentrations of vitamin A, vitamin C, vitamin $\mathrm{E}$ adjusted for lipids, and $\mathrm{Zn}$ included separately in models for each cytokine. Models were then run, which included all the micronutrient variables together in models for each cytokine to control for any interactions between the different micronutrients analysed. Thus, results are presented adjusted for micronutrient concentrations all together, age and CRP concentrations, and further adjusted for BMI. Statistical significance was set at a probability level of $<0.05$ and $<0.1$ for interactions. Data were analysed using ordered logistics procedure (OLOGIT) in the STATA (version 10) software (STATACorp LP).

\section{Results}

A total of 280 women were enrolled in the study. The anthropometric and metabolic characteristics of the women at the beginning of the study are summarised in Table 1 . The prevalence of obesity and overweight was 43.9 and $36.4 \%$, respectively. In addition, $21.7 \%$ had hypertriacylglycerolaemia, $37.8 \%$ had high total cholesterol and $11.8 \%$ of the women had low levels of HDL. Overall, 4, 15.5 and $16.7 \%$ of women had deficiencies of vitamin $\mathrm{C}$, vitamin $\mathrm{E}$ and $\mathrm{Zn}$, respectively, while no women were found to have vitamin A deficiency. When adjusting for total lipids, $11 \%$ of the participants had vitamin E deficiency.

Ordered logistical regression models were first used to analyse the associations between measures of obesity and adiposity with probability of higher cytokine and chemokine levels. Women with higher BMI, a greater percentage of 
Table 1. Physical and biochemical characteristics of the subjects

(Mean values and standard deviations)

\begin{tabular}{|c|c|c|c|c|c|c|c|c|}
\hline & \multicolumn{2}{|c|}{ Normal ( $n$ 52) } & \multicolumn{2}{|c|}{$\begin{array}{l}\text { Overweight } \\
\quad(n \text { 104) }\end{array}$} & \multicolumn{2}{|c|}{ Obese $(n 124)$} & \multicolumn{2}{|c|}{ Total $(n 280)$} \\
\hline & Mean & SD & Mean & SD & Mean & SD & Mean & SD \\
\hline Age (years) & $33.9^{\mathrm{a}}$ & $6 \cdot 8$ & $37 \cdot 2^{\mathrm{a}}$ & $7 \cdot 8$ & $38 \cdot 2^{\mathrm{b}}$ & 7.5 & 37 & 7.5 \\
\hline Weight (kg) & $53.9^{\mathrm{a}}$ & 4.9 & $62 \cdot 9^{\mathrm{b}}$ & $5 \cdot 1$ & $78 \cdot 9^{\mathrm{C}}$ & $10 \cdot 4$ & $68 \cdot 2$ & $12 \cdot 7$ \\
\hline BMI $\left(\mathrm{kg} / \mathrm{m}^{2}\right)$ & $22 \cdot 9^{\mathrm{a}}$ & 1.5 & $27 \cdot 5^{\mathrm{b}}$ & 1.4 & $34.5^{\mathrm{c}}$ & 4.1 & 29.7 & 5.5 \\
\hline Abdominal fat (\%) & $36 \cdot 9^{\mathrm{a}}$ & $5 \cdot 1$ & $42 \cdot 9^{b}$ & $3 \cdot 7$ & $47 \cdot 1^{\mathrm{c}}$ & 4.1 & $43 \cdot 6$ & $5 \cdot 6$ \\
\hline Waist circumference $(\mathrm{cm})$ & $76 \cdot 5^{\mathrm{a}}$ & $15 \cdot 1$ & $86 \cdot 3^{\mathrm{b}}$ & 4.9 & $99.9^{\mathrm{c}}$ & 8.9 & $90 \cdot 3$ & 11.5 \\
\hline Waist:height ratio & $0.4^{\mathrm{a}}$ & 0.03 & $0.5^{\mathrm{b}}$ & 0.03 & $0.6^{c}$ & 0.1 & 0.5 & 0.1 \\
\hline Vitamin A $(\mu \mathrm{g} / \mathrm{l})$ & $462^{\mathrm{b}}$ & 109 & $501^{a}$ & 70 & 481 & 119 & 485 & 114 \\
\hline Vitamin E:lipids ( $\mu \mathrm{mol} / \mathrm{mmol})$ & $2 \cdot 9$ & 0.8 & $2 \cdot 8$ & 0.9 & $2 \cdot 8$ & 0.7 & $2 \cdot 8$ & 0.8 \\
\hline Vitamin C ( $\mu \mathrm{g} / \mathrm{ml})$ & $5 \cdot 1$ & $2 \cdot 2$ & 5.4 & $2 \cdot 2$ & 5.4 & $2 \cdot 2$ & $5 \cdot 2$ & $2 \cdot 2$ \\
\hline $\mathrm{Zn}(\mathrm{mg} / \mathrm{l})$ & $1 \cdot 2$ & 0.5 & $1 \cdot 2$ & 0.6 & $1 \cdot 2$ & 0.7 & 1.2 & 0.6 \\
\hline Leptin (pg/ml) & $16 \cdot 1^{\mathrm{a}}$ & $9 \cdot 6$ & $25 \cdot 7^{b}$ & $11 \cdot 1$ & $44 \cdot 6^{c}$ & $18 \cdot 4$ & $32 \cdot 2$ & 18.5 \\
\hline CRP (mg/l) & $2 \cdot 7^{\mathrm{a}}$ & $3 \cdot 3$ & $4 \cdot 3^{b}$ & $3 \cdot 1$ & $6 \cdot 7^{\mathrm{c}}$ & 3.7 & $5 \cdot 1$ & 3.5 \\
\hline
\end{tabular}

CRP, C-reactive protein.

a,b,c Mean values within a row with unlike superscript letters were significantly different (Tukey test, $P<0.05$ )

abdominal fat or a greater waist-to-height index were found to have an increased probability of having higher concentrations of IL-6 (OR 1.05, 95\% CI 1.01, 1.09, $P=0 \cdot 01$; OR $1.03,95 \%$ CI $1.00,1 \cdot 07, P=0.05$ and OR $12.89,95 \% \mathrm{CI}$ $0 \cdot 92,179 \cdot 5, P=0 \cdot 04$, respectively). No significant association was found between increased odds for the other cytokines and other anthropometric measures of obesity (Table 2). No association was found between leptin and cytokines when included in the models.

The ordered logistical regression models were then used to analyse the associations between serum micronutrient concentrations and the probability of higher cytokine and chemokine concentrations. The OR of having higher concentrations of TNF- $\alpha$, IL-6, IL-10 and IL-12 were reduced for women with higher concentrations of plasma $\mathrm{Zn}$ (OR 0.63, 95\% CI $0 \cdot 42$, $0.96, P=0.03$; OR $0.57,95 \%$ CI $0.39,0.86, P=0.025$; OR 0.63 , $95 \%$ CI $0.41,0.96, P=0.04$ and OR $0.62,95 \%$ CI $0.41,0.95$, $P=0.03$, respectively) (Table 3 ). Higher concentrations of vitamin A were associated with reduced risks of higher levels of IL-1 and IL-12 (OR 0.97, 95\% CI 0.95, 0.99, $P=0.03$; OR $0.97,95 \%$ CI $0.94,0.99, P=0.03$, respectively). This association disappears when adjusting for BMI. No associations between inflammation markers and vitamin $\mathrm{C}$ or vitamin $\mathrm{E}$ adjusted for lipids were found.

\section{Discussion}

The present study has characterised the relationship between inflammatory cytokine markers and measures of obesity and adiposity among women, and also how serum concentrations of micronutrients are associated with inflammatory cytokine markers. Higher concentrations of plasma $\mathrm{Zn}$ were associated with reduced levels of inflammatory cytokines.

The significant association found between IL-6 and measures of obesity and body composition is consistent with other studies which have found that this cytokine is associated with adiposity $^{(37)}$. Mohamed-Ali et al. ${ }^{(38)}$, for example, reported that approximately $30 \%$ of in vivo circulating levels of IL-6 was secreted by adipose tissue and that this release was greater in obese subjects. Vozarova et al. ${ }^{(39)}$ also found that fasting plasma IL- 6 concentrations were positively related to adiposity but negatively related to insulin action in Pima Indians. In contrast to our findings, TNF- $\alpha$ also has been reported to be significantly elevated in obese, insulin-resistant rodents and humans ${ }^{(40,41)}$. However, Kern et al. ${ }^{(41)}$, reported that IL-6 levels were much higher in both adipose tissue and plasma in obese subjects while no significant differences in TNF- $\alpha$ secretion by adipose tissue depots was found between obese and lean subjects. These inconsistent observations support the lack of association for this cytokine and adiposity measures found in the present study.

The lack of correlation between leptin levels with any of the inflammation cytokine markers is not consistent with reports from other studies ${ }^{(42)}$. However, the relationship between leptin and inflammatory cytokines reported in previous studies is not always consistent. For example, an inverse relationship between leptin and IL-6 as well as other inflammation markers was found among rheumatoid arthritis patients ${ }^{(43)}$. In vitro studies of human and rat monocytes have also found that leptin enhances the expression of proinflammatory cytokines like IL-6, IL-8 and TNF- $\alpha^{(44,45)}$. Xiao et $a l .{ }^{(46)}$, in contrast, reported a reduction in IL-6 and TNF- $\alpha$ among primates immunised with endotoxin after treating them with leptin. The lack of an association between leptin and inflammation found in this study may be due to the low grade of inflammation and cytokine concentrations seen in obesity, which may not provide adequate statistical power relative to that reported in acute inflammation states or in cell lines. Overall, these findings suggest that, in this population, leptin may not be directly involved in the pathway that leads to chronic inflammation among obese individuals.

The reduced odds of higher levels of the inflammatory markers TNF- $\alpha$, IL- 6 and IL-12 among women with higher Zn concentration is similar to the findings by Bao et al. ${ }^{(47)}$. They reported that $\mathrm{Zn}$ supplementation of elder subjects was associated with decreased concentrations of plasma inflammatory 
cytokines. Much research has been carried out about $\mathrm{Zn}$ concerning the pathways that may be involved in the association of $\mathrm{Zn}$ and the immune system; there is still no consensus. However, the strongest theory involves $\mathrm{Zn}$ regulation of Zn-dependent enzymes related with the immune system ${ }^{(48)}$. One of these enzymes is ZAG, a soluble cytokine that down-regulates the expression of TNF- $\alpha$. Bao et al. ${ }^{(49)}$ consider ZAG an important beneficial factor for obesity ${ }^{(49)}$. The expression of ZAG is down-regulated in obese subjects ${ }^{(50)}$. Thus, Zn may protect against chronic inflammation through the expression of ZAG and its down-regulation effect on TNF- $\alpha$.

In the present study, the odds of having higher levels of the anti-inflammatory cytokine IL-10 was also reduced with high $\mathrm{Zn}$ concentrations. Similarly, it has been observed in both in vitro and human studies that $\mathrm{Zn}$ supplementation decreases IL-10 concentrations ${ }^{(51,52)}$. In addition, obese individuals have increased pro-inflammatory and anti-inflammatory cytokines $^{(53)}$. Obese women, for example, before a gastric bypass, had significantly higher IL-10 concentrations compared to normal-weight women ${ }^{(54)}$. TNF- $\alpha$, IL-6 and IL-10 concentrations were significantly higher in obese patients with heart failure than in non-obese patients with mild heart failure $^{(55)}$. This has also been observed in patients during an infectious disease episode, where the concentrations of the anti-inflammatory cytokine IL-10 are increased in response to increased inflammatory cytokine concentrations in order to minimise damage to the host and to avoid tissue damage. This simultaneous response then allows the immune response to return to homeostasis once the infection or the antigen is cleared $^{(56)}$. Something similar might be occurring in obese or overweight individuals, or with Zn deficiency, where elevated concentrations of IL-10 may be part of a mechanism to counteract the effect of the pro-inflammatory cytokines ${ }^{(53)}$. The anti-inflammatory effect of IL-10 has been attributed to its ability to inhibit the maturation of antigen-presenting cells, but preserving the capacity of the cells to load the antigens. Also, it has been suggested that it may produce a pro-inflammatory response when antigen-loaded antigenpresenting cells activate local immune responses ${ }^{(57)}$. Thus, $\mathrm{Zn}$ concentrations may play an important role in the pleiotropic effects of IL-10.

Vitamin A is recognised to down-regulate the expression of inflammation markers and promote a Th2 immune response by binding with its membrane receptor retinoic acid receptor- $\alpha$ that inhibits the production of interferon- $\gamma$, a mediator of other inflammation markers ${ }^{(16,58)}$. In this study, higher concentrations of vitamin A are associated with decreased odds of having higher levels of inflammation markers, although this association is only found for the cytokines IL-1 and IL-12 and is not as great as that seen with Zn. When adjusting for obesity, no effect was found between vitamin A concentrations and the levels of inflammation markers. These results may reflect the fact that subjects in this study were not vitamin A-deficient. In vitamin A deficiency, there is an increase of pro-inflammatory cytokines that promotes a Th1-type inflammatory response, while the production of anti-inflammatory cytokines, such as IL-10, is reduced ${ }^{(59,60)}$. 
For example, in Indonesian children, vitamin A deficiency was associated with a higher Th1 response ${ }^{(61)}$. Similarly, the production of IL-10 was negatively associated with vitamin A stores in adult men ${ }^{(62)}$. Thus, vitamin A deficiency increases the production of pro-inflammatory cytokines and reduces the concentration of anti-inflammatory cytokines.

Vitamin $\mathrm{C}$ and vitamin E:lipids were not associated with any of the cytokines studied. Findings on the relationship between vitamin $\mathrm{C}$ and vitamin $\mathrm{E}$ with inflammatory markers have been inconsistent $^{(18-20,63-66)}$. For example, intakes of vitamin $C$ and vitamin E were not associated with CRP or IL-6 in 5181 participants from the Multi-Ethnic Study of Atherosclerosis ${ }^{(64)}$. In contrast, Mah et al. ${ }^{(65)}$ found an inverse relationship between vitamin $\mathrm{C}$ status and inflammatory markers among obese men compared with a group of lean adult men in a cross-sectional study, but found no association between vitamin $\mathrm{E}$ status and CRP concentrations or inflammatory cytokines. Similarly, Wannamethee et $a{ }^{(19)}$ reported that vitamin C status was inversely associated with CRP concentrations and lower endothelial dysfunction in men with no history of CVD or diabetes. These epidemiological studies show that vitamin $\mathrm{C}$ status is associated with CRP while no associations have been found between vitamin $\mathrm{C}$ status and vitamin $\mathrm{E}$ status with the inflammatory cytokine response, similar to the findings in the present study.

Supplementation studies have also reported mixed results. Bruunsgaard et al. ${ }^{(66)}$ found no difference in the concentration of IL- 6 or TNF- $\alpha$ among adult men supplemented with vitamins $\mathrm{C}$ and $\mathrm{E}$ for 36 months compared to men who received a placebo. In contrast, Block et al. ${ }^{(20)}$ reported that vitamin C supplementation for 2 months was associated with a $24 \%$ reduction in plasma concentrations of the inflammatory marker CRP. Increases in vitamin $\mathrm{E}$ plasma concentrations after supplementing with vitamin $\mathrm{E}$ and vitamin $\mathrm{C}$ for 2 weeks were associated with lower TNF- $\alpha$ concentrations in adult men with impaired fasting glucose ${ }^{(67)}$. These inconsistencies regarding the effect of vitamin $\mathrm{E}$ on inflammation may be due to the different forms of this vitamin that are found in the diet or given as supplements. Berdnikov et al. ${ }^{(18)}$, for example, reported that the $\alpha$-tocopherol and $\mathrm{D}-\alpha$-tocopherol isoforms of vitamin $\mathrm{E}$ have opposing immunoregulatory effects on the inflammatory response. The lack of consistency in the clinical trials may also be explained by the differences in the supplementation period that range from 2 weeks to 3 years and/or the doses given. More studies are needed to understand the effect of vitamin $\mathrm{C}$ and vitamin $\mathrm{E}$ on inflammatory markers.

A number of methodological limitations of our study need to be addressed. The cross-sectional design of the study complicates efforts to determine causality between body composition and obesity, serum micronutrient concentrations and inflammatory cytokines. For example, it is not possible to determine whether elevated inflammatory cytokines may be affecting serum micronutrient concentrations or whether micronutrient concentrations are affecting inflammatory cytokine levels. The effects of inflammation on micronutrient concentrations were partly controlled by including CRP in all the models. There were no significant differences in the 
associations between models that included CPR compared to models that did not include this inflammatory marker, suggesting that micronutrient concentrations could be affecting inflammatory cytokine levels.

Associations were found between specific micronutrient serum concentrations and the odds of having higher concentration of inflammatory markers. The findings in the present study suggest that micronutrients play a different role in low-grade chronic inflammation among individuals with differing degrees of adiposity and obesity. Overall, it was found that higher $\mathrm{Zn}$ concentration is associated with reduced risks of higher concentration of inflammation markers. These results are preliminary and so must be interpreted with caution. It is important to continue addressing the relationship between these micronutrients and the inflammatory response especially among populations that differ in the prevalence of overweight and obesity. Such efforts will determine whether such relationships change with changing adiposity, and so establish how specific nutrients may be interacting with adipose tissue to regulate the production of inflammatory cytokines and so modify low-grade inflammation occurring in obesity.

\section{Acknowledgements}

The authors wish to acknowledge the work of the nutritionists who participated in the fieldwork, Rosa María Rodríguez and Shadia Elian, and also the health clinics in the communities where the study took place. The authors declare no conflicts of interest. The present study was partially funded by CONACYT Project no. SEP-2004-C01-48183. The authors' responsibilities were as follows: G. Z. participated in the data analysis and interpretation, and wrote the initial draft of the manuscript. K. Z. L. contributed to the study design, data analysis and interpretation. O. P. G. contributed with the concept and study design, study implementation, and contributed to the writing of the manuscript. M. d. C. C. contributed in the writing of the manuscript. T. A. assisted in the data management and interpretation. L. M. S. contributed with the analysis of the cytokines. J. L. R. contributed to the concept and study design and provided important intellectual content to the manuscript.

\section{References}

1. Cutles DM, Glaeser EL \& Shapiro JM (2003) Why have Americans become more obese? J Econ Perspect 17, 93-118.

2. Lenz M, Richter T \& Muhlhauser I (2009) The morbidity and mortality associated with overweight and obesity in adulthood. Dtsch Ärztebl Int 106, 641-648.

3. Waring ME, Roberts MB, Parker DR, et al. (2009) Documentation and management of overweight and obesity in primary care. J Am Board Fam Med 22, 544.

4. Olaiz-Fernández G, Rivera-Dommarco J, Shamah-Levy T, et al. (2006) Encuesta Nacional de Salud y Nutrición 2006 (ENSANUT). Cuernavaca: Instituto Nacional de Salud Pública.

5. Maffei M, Funicello M, Vottari T, et al. (2009) The obesity and inflammatory marker haptoglobin attracts monocytes via interaction with chemokine ( $\mathrm{C}-\mathrm{C}$ motif) receptor 2 (CCR2). BMC Biol 7, 1-14.

6. Rodríguez-Rodríguez E, Perea JM, López-Sobaler AM, et al. (2009) Obesidad, resistencia a la insulina y aumento de los niveles de adipoquinas: importancia de la dieta y el ejercicio físico (Obesity, insulin resistance and increase in adipokine levels: importance of the diet and physical activity). Nutr Hosp 24, 415-421.

7. Stofkova A (2009) Leptin and adiponectin: from energy and metabolic dysbalance to inflammation and autoimmunity. Endocr Regul 43, 157-168.

8. La Cava A \& Matarese G (2004) The weight of leptin in immunity. Nat Rev Immunol 4, 371-379.

9. De Rosa V, Procaccini C, Cali G, et al. (2007) A key role of leptin in the control of regulatory $\mathrm{T}$ cell proliferation. Immunity 26, 241-255.

10. Lord GM, Matarese G, Howard JK, et al. (2001) The bioenergetics of the immune system. Science 292, 855-856.

11. García O, Long K \& Rosado J (2009) Impact of micronutrient deficiencies on obesity. Nutr Rev 10, 559-572.

12. Cristos S, Mantzoros C, Ananda S, et al. (1998) Zinc may regulate serum leptin concentrations in humans. $J$ Am Coll Nutr 17, 270-275.

13. Gomez-Garcia A, Hernandez-Salazar E, Gonzalez-Ortiz M, et al. (2006) Effect of oral zinc administration on insulin sensitivity, leptin and androgens in obese males. Rev Med Chil 134, 279-284.

14. Kumar M \& Scarpace P (1998) Differential effects of retinoic acid on uncoupling protein-1 and leptin gene expression. J Endocrinol 152, 237-243.

15. Bonet M, Oliver J, Pico C, et al. (2000) Opposite effects of feeding a vitamin A-deficient diet and retinoic acid treatment on brown adipose tissue uncoupling protein 1 (UCP1), UCP2 and leptin expression. J Endocrinol 166, 511-517.

16. Dawson H, Solana G, Beal M, et al. (2009) Localized Th1-, Th2-, T regulatory cell-, and inflammation-associated hepatic and pulmonary immune responses in ascaris suum-infected swine are increased by retinoic acid. Infect Immun $\mathbf{7 7}$, 2576-2587.

17. Tabak C, Smit HA, Rasanen L, et al. (1999) Dietary factors and pulmonary function: a cross sectional study in middle aged men from three European countries. Thorax 54, 1021-1026.

18. Berdnikovs S, Abdala-Valencia H, McCary C, et al. (2009) Isoforms of vitamin $\mathrm{E}$ have opposing immunoregulatory functions during inflammation by regulating leukocyte recruitment. J Immunol 182, 4395-4405.

19. Wannamethee SG, Lowe GD, Rumley A, et al. (2006) Associations of vitamin $\mathrm{C}$ status, fruit and vegetable intakes, and markers of inflammation and hemostasis. Am J Clin Nutr $\mathbf{8 3}, 567-574$.

20. Block G, Jensen C, Dietrich M, et al. (2004) Plasma C-reactive protein concentrations in active and passive smokers: influence of antioxidant supplementation. J Am Coll Nutr 23, $141-147$.

21. Esmaillzadeh A \& Azadbakht L (2012) Legume consumption is inversely associated with serum concentrations of adhesion molecules and inflammatory biomarkers among Iranian women. J Nutr 142, 334-339.

22. Ezmaillzadeh A, Kimiagar M, Mehrabi Y, et al. (2007) Dietary patterns and markers of systemic inflammation among Iranian women. J Nutr 137, 992-998.

23. Salas-Salvado J, Casas-Agustench P, Murphy MM, et al. (2008) The effect of nuts on inflammation. Asia Pac J Clin Nutr 17, 333-336. 
24. Dupont W \& Plummer W (1997) PS power and sample size calculations. Control Clin Trials 18-274.

25. Lohman T, Roche A \& Martorell R (1998) Anthropometric Standardization Reference Manual. Champaign, IL: Human Kinetics.

26. World Health Organization (2000) Obesity: Preventing and Managing the Global Epidemic. Geneva: WHO.

27. James PT, Leach R, Kalamara E, et al. (2001) The worldwide obesity epidemic. Obes Res 9, S228-S233.

28. World Health Organization (2002) Technical Report Series 894: Obesity: Preventing and Managing the Global Epidemic. Geneva: WHO.

29. Hill AM, LaForgia J, Coates AM, et al. (2007) Estimating abdominal adipose tissue with DXA and anthropometry. Obesity (Silver Spring) 15, 504-510.

30. Hess SY, Peerson J, King J, et al. (2007) Use of serum zinc concentration as an indicator of population zinc status. Food Nutr Bull 28, S403-S419.

31. Friesdwald WT, Levy RI \& Fredrickson DD (1972) Estimation of the concentration of lowdensity lipoprotein cholesterol in plasma, without the use of preparative centrifuge. Clin Chem 18, 499-502.

32. Gibson R (2005) Assessment of the status of vitamins A, D, and E. In Principles of Nutritional Assessment. New York, NY: Oxford University Press.

33. Food and Nutrition Board I (editor) (2000) Vitamin E. In Dietary Reference Intakes for Vitamin C, Vitamin E, Selenium, and Carotenoids. Washington, DC: National Academies Press.

34. Mexican Health Ministry (1994) Para la prevención, tratamiento y control de la diabetes mellitus en la atención primaria. (For the prevention, Treatment and Control of Diabetes Mellitus in Primary Care). Norma oficial Mexicana NOM-015-SSA2-1994. México: Secretaria de Salud.

35. National Cholesterol Education Program (NCEP) Expert Panel on Detection E, and Treatment of High Blood Cholesterol in Adults (Adult Treatment Panel III) (2002) Third Report of the National Cholesterol Education Program (NCEP) Expert Panel on Detection, Evaluation, and Treatment of High Blood Cholesterol in Adults (Adult Treatment Panel III) final report. Circulation 106, 3143-3421.

36. Agresti A (1990) Categorical Data Analysis. New York, NY: John Wiley, Sons, Inc.

37. Fried S, Bunkin D \& Greenberg A (1998) Omental and subcutaneous adipose tissues of obese subjects release interleukin-6:depot difference and regulation by glucocorticoid. J Endocrinol Metab 83, 847-850.

38. Mohamed-Ali V, Goodrick S, Rawesh A, et al. (1997) Subcutaneous adipose tissue releases interleukin-6, but not tumor necrosis factor-a, in vivo. J Clin Endocrinol Metab 82, 4195-4201.

39. Vozarova B, Weyer C, Hanson K, et al. (2001) Circulating interleukin-6 in relation to adiposity, insulin action and insulin secretion. Obes Res 9, 414-417.

40. Kern P, Saghizadeh M, Ong M, et al. (1995) Leptin induces an inflammatory phenotype in lean Wistar rats. J Clin Invest $\mathbf{9 5}$, 2111-2119.

41. Kern P, Ranganathan S, Li C, et al. (2001) Adipose tissue tumor necrosis factor and interleukin-6 expression in human obesity and insulin resistance. Am J Physiol Renal Physiol 280, E745-E751.

42. Lord GM, Matarese G, Howard JK, et al. (1998) Leptin modulates the T-cell immune response and reverses starvationinduced immunosuppression. Nature 394, 897-901.
43. Popa C, Netea G, Radstake D, et al. (2005) Markers of inflammation are negatively correlated with serum leptin in rheumatoid arthritis. Ann Rheum Dis 64, 1195-1198.

44. Lofreda S, Yang SQ, Lin S, et al. (1998) Leptin regulates proinflammatory immune responses. FASEB J 12, 57-65.

45. Zarkesh-Esfahani H, Pockley G, Metcalfe RA, et al. (2001) High-dose leptin activates human leukocytes via receptor expression on monocytes. J Immunol 167, 4593-4599.

46. Xiao E, Xia-Zhang L, Vulliemoz NR, et al. (2003) Leptin modulates inflammatory cytokine and neuroendocrine responses to endotoxin in the primate. Endocrinology $\mathbf{1 4 4}$ $4350-4353$.

47. Bao B, Prasad S, Beck F, et al. (2010) Zinc decreases C-reactive protein, lipid peroxidation, and inflammatory cytokines in elderly subjects: a potential implication of zinc as an atheroprotective agent. Am J Clin Nutr 91, 1634-1641.

48. Mracek T, Gao D, Tzanavari T, et al. (2010) Downregulation of zinc- $\alpha 2$-glycoprotein in adipose tissue and liver of obese $\mathrm{ob} / \mathrm{ob}$ mice and by tumour necrosis factor-a in adipocytes. $J$ Endocrinol 204, 165-172.

49. Bao Y, Bing C, Hunter L, et al. (2005) Zinc- $\alpha 2$-glycoprotein, a lipid mobilizing factor, is expressed and secreted by human (SGBS) adipocytes. FEBS Lett 579, 41-47.

50. Marredes M, Martinez J \& Moreno M (2008) ZAG, a lipid mobilizing adipokine, is downregulated in human obesity. J Physiol Biochem 41, 61-66.

51. Metz CH, Schroder AK, Overbeck S, et al. (2007) T-helper type 1 cytokine release is enhanced by in vitro zinc supplementation due to increased natural killer cells. Nutrition 23, $157-163$.

52. Sandstead HH, Prasad AS, Penland JG, et al. (2008) Zinc deficiency in Mexican American children: influence of zinc and other micronutrients on $\mathrm{T}$ cells, cytokines, and antiinflammatory plasma proteins. Am JClin Nutr 88, 1067-1073.

53. Fain JN (2010) Release of inflammatory mediators by human adipose tissue is enchanced in obesity and primarily by the nonfat cells: a review. Mediators Inflamm 2010, 513948.

54. Dalmas E, Rouault C, Abdennour M, et al. (2011) Variations in circulating inflammatory factors are related to changes in calorie and carbohydrate intakes early in the course of surgery-induced weight reduction. Am J Clin Nutr 94, 450-458.

55. Hamdy NM (2011) Relationship between pro-anti-inflammatory cytokines, T-cell activation and CA 125 in obese patients with heart failure. Med Sci Monit 17, CR174-CR179.

56. Sanjabi S, Zenewicz L, Kamanaka M, et al. (2009) Anti- and pro-inflammatory roles of TGF- $\beta$, IL-10 and IL-22 in immunity and autoimmunity. Curr Opin Pharmacol 9, 447-453.

57. Mocellin S, Panelli MC, Wang E, et al. (2003) The dual role of IL-10. Trends Immunol 24, 36-43.

58. Kumar MV, Sunvold GD \& Scarpace PJ (1999) Dietary vitamin A supplementation in rats: suppression of leptin and induction of UCP1 mRNA. J Lipid Res 40, 824-829.

59. Long KZ \& Santos JL (1999) Vitamins and the regulation of the immune response. Pediatr Infect Dis J 18, 284-290.

60. Aukrust P, Müller F, Ueland T, et al. (2000) Decreased vitamin A levels in common variable immunodeficiency: vitamin A supplementation in vivo enhances immunoglobulin production and downregulates inflammatory responses. Eur J Clin Invest 30, 252-259.

61. Wieringa FT, Dijkhuizen MA, West CE, et al. (2004) Reduced production of immunoregulatory cytokines in vitamin A- and zinc-deficient Indonesian infants. Eur J Clin Nutr 58, 1498-1504.

62. Ahmad SM, Haskell MJ, Raqib R, et al. (2009) Vitamin A status is associated with T-cell responses in Bangladeshi men. Br J Nutr 102, 797-802. 
63. Beyer R (1994) The role of ascorbate in antioxidant protection of biomembranes: interaction with vitamin $\mathrm{E}$ and coenzyme Q. J Bioenerg Biomembr 26, 349-358.

64. De Oliveira Otto MC, Alonso A, Lee DH, et al. (2011) Dietary micronutrient intakes are associated with markers of inflammation but not with markers of subclinical atherosclerosis. J Nutr 141, 1508-1515.

65. Mah E, Matos MD, Kawiecki D, et al. (2011) Vitamin C status is related to proinflammatory responses and impaired vascular endothelial function in healthy, college-aged lean and obese men. J Am Diet Assoc 111, 737-743.

66. Bruunsgaard H, Poulsen HE, Pedersen BK, et al. (2003) Long-term combined supplementations with alpha-tocopherol and vitamin $C$ have no detectable anti-inflammatory effects in healthy men. $J$ Nutr 133, 1170-1173.

67. Rizzo MR, Abbatecola AM, Barbieri M, et al. (2008) Evidence for anti-inflammatory effects of combined administration of vitamin $\mathrm{E}$ and $\mathrm{C}$ in older persons with impaired fasting glucose: impact on insulin action. J Am Coll Nutr 27, 505-511. 